\title{
Decreased fecundity among male lead workers
}

\author{
C-Y Shiau, J-D Wang, P-C Chen
}

Occup Environ Med 2004;61:915-923. doi: 10.1136/oem.2004.014944

\begin{abstract}
Aims: To investigate time to pregnancy (TTP) in male lead workers in order to determine the dose-response relation between blood lead and decreased fecundity. Methods: A total of 163 currently employed married male lead battery workers were classified into five categories of exposure based on questionnaire information and annual individual blood lead measurement. Information pertaining to the TTP was collected using personal interviews with 133 men and their spouses, with 280 valid pregnancies. The fecundability ratios (FRs) were calculated with the Cox discrete proportional hazard regression technique to evaluate the effects of lead exposure.

Results: After other factors associated with TTP were controlled for, there was a dose-response relation between blood lead level and TTP. The measured FRs were 0.90 (95\% $\mathrm{Cl} 0.61$ to 1.34$), 0.72$ (0.46 to $1.11), 0.52(0.35$ to 0.77$)$, and $0.40(0.27$ to 0.59$)$ for concurrent blood lead levels of $<20,20-29,30-$ 39 , and $\geqslant 40 \mu \mathrm{g} / \mathrm{dl}$, respectively. Paired self comparison was also performed for 41 couples that had pregnancies prior to lead exposure and pregnancies with male occupational lead exposure. The TTP was prolonged for 0.15 cycles by a $1 \mu \mathrm{g} / \mathrm{dl}$ increase in blood lead. Conclusions: These results corroborate the hypothesis that a raised blood lead level affects fecundity. A blood lead level of less than $40 \mu \mathrm{g} / \mathrm{dl}$ may still significantly prolong TTP.
\end{abstract}

See end of article for authors' affiliations

Correspondence to: Dr P-C Chen, Institute of Occupational Medicine and Industrial Hygiene, National Taiwan University College of Public Health, 1, Section 1, Jen-Ai Road, Taipei 10063, Taiwan; pchen@ntu.edu.tw

Accepted 19 June 2004

$\mathrm{T}$ oxic lead exposure is one of the most prevalent occupational and environmental health problems in the world today. Epidemiological studies have shown male reproductive toxicity such as semen quality and endocrine function, ${ }^{1-4}$ and male mediated adverse pregnancy outcomes such as spontaneous abortion, congenital malformation, and preterm birth..$^{5-8}$ Some studies ${ }^{9-11}$ showed reduced fertility using a measure of fertility or infertility rate among males and families exposed to lead contamination, whereas another study $^{12}$ did not. Moreover, three studies ${ }^{13-15}$ only revealed weak effects of decreased fertility using a measure of time to pregnancy (TTP) among the wives of the husbands exposed to lead contamination. There were limited and conflicting results between lead exposure and reduced fertility of the men, with no clear dose-response relation, especially at a threshold level.

Lead effect on human male fertility has been postulated to occur at blood levels greater than $40 \mu \mathrm{g} / \mathrm{dl},{ }^{3}$ which is the current occupational standard in the United States ${ }^{16}$ and many other countries, including Taiwan. The first evidence of such alterations at even lower blood lead level $(\mathrm{PbB})$, for example, $20-50 \mu \mathrm{g} / \mathrm{dl}$ has, however, appeared in a few animal studies. ${ }^{17}{ }^{18} \mathrm{Ng}$ and colleagues ${ }^{2}$ also noted that luteinising hormone and follicle stimulating hormone showed a moderate increase in relation to $\mathrm{PbB}$ in the range $10-40 \mu \mathrm{g} / \mathrm{dl}$. Circumstantial evidence suggests that occupational hazards of lead contamination may occur at less than the occupational threshold limit value of $40 \mu \mathrm{g} / \mathrm{dl}$ and may be associated with adverse effects on human sperm. ${ }^{19}$ However, Bonde and colleagues ${ }^{4}$ suggested that adverse effects of lead on sperm concentration and susceptibility to acid induced denaturation of sperm chromatin are unlikely at blood lead concentrations below $45 \mu \mathrm{g} / \mathrm{dl}$. The lowest level of lead effect on male reproduction depends on different species or reproductive endpoints. Thus, we do not know whether a PbB of $40 \mu \mathrm{g} / \mathrm{dl}$ is enough to protect male workers in view of male and male mediated reproductive effects.

Because of the difficulty in obtaining human semen and the conservative nature of sexual norms in traditional Chinese culture, we selected the TTP of wives as a surrogate

measure of male fecundity, as proposed by Baird and colleagues. ${ }^{20}$ TTP is considered to be an estimate of fecundity and is a composite measure of gametogenesis, transport of germ cells, fertilisation, transport of the embryo, and early survival of the fetus. ${ }^{21}$ The data pertaining to the TTP of wives collected using a brief questionnaire is valid at a group level with a recall time of 14 years or more. ${ }^{22}$ Disadvantages, however, include susceptibility to recall and selection biases, ${ }^{23}$ and the need for data pertaining to several potential confounders. $^{20}$ Thus, avoidance of biases and control of confounding are crucial to any empirical study using TTP.

This study was conducted, retrospectively, in a face-to-face collection of TTP information from couples whose husbands were exposed to lead in their occupations within a broad range. The aim of the study was to determine the doseresponse relation between blood lead and decreased fecundity, and investigated whether a $\mathrm{PbB}$ of $40 \mu \mathrm{g} / \mathrm{dl}$ provides adequate protection to lead workers.

\section{METHODS}

\section{Study design and subjects}

TTP was studied among the wives of men biologically monitored for exposure to lead. The study population consisted of all 163 married male workers employed at a lead battery plant of Taiwan in November 1998. All study participants provided informed consent, which was approved by the National Taiwan University College of Public Health Ethic Review Board. We conducted face-to-face interviews with all married male workers and their wives. At the plant, we interviewed each man first to gather the information on his demography, occupation, lifestyle, and past medical history. Our research physician and nurse then conducted a face-to-face interview with each worker's wife at home with inquiries relating to pregnancies or infertility histories during the period 1984-98.

Abbreviations: $A A$, artificial abortion; $F R$, fecundability ratio; $I C L$ index of cumulative blood lead; IUD, intrauterine device; $\mathrm{PbB}$, blood lead level; SA, spontaneous abortion; SD, standard deviation; TTP, time to pregnancy 


\section{Main messages}

- The present study corroborates the hypothesis that decreased fecundity is significantly associated with male exposure to lead when concurrent blood lead level is less than $40 \mu \mathrm{g} / \mathrm{dl}$.

\section{Exposure assessment}

Every worker was required to have blood lead levels checked during an annual health examination. The blood lead content was measured using inductively coupled plasma mass spectrometry (ICPMS) in a clinical laboratory at the Taipei Veteran's General Hospital. The laboratory has regularly participated in our national quality control programme for blood lead determination since $1990^{24}$ and serves as one of the reference laboratories in Taiwan.

The employment history and lead level were used as the basis for exposure categorisation. There were 153 TTPs without exposure and 127 TTPs whose husbands were exposed to lead. Among those with lead exposure, male exposure to lead was assessed within 80 days (the estimated period of spermatogenesis) prior to the time unprotected intercourse began. However, 53 occurred outside the period of blood lead sampling, and we used the average blood lead concentration before and after the TTP. TTPs were categorised into five groups based on blood lead concentrations (the concurrent $\mathrm{PbB}$ at the beginning of the calendar year when TTP started): non-exposed (pregnancy occurred prior to husband working in lead exposure environments); low (blood lead $<20 \mu \mathrm{g} / \mathrm{dl}$ ); moderate (blood lead 20-29 $\mu \mathrm{g} / \mathrm{dl}$ ); high $(30-39 \mu \mathrm{g} / \mathrm{dl})$; and very high exposed $(\geqslant 40 \mu \mathrm{g} / \mathrm{dl})$.

We also estimated the index of cumulative blood lead level (ICL) before the beginning of the calendar year when the TTP started. ${ }^{25}$ Briefly, the ICL was calculated by the following formula: $\mathrm{ICL}=\left[0.5\left(\mathrm{PbB}_{\mathrm{i}}+\mathrm{PbB}_{\mathrm{i}+1}\right) \Delta \mathrm{t}_{\mathrm{i}}\right]$, expressed in $\mu \mathrm{g} / \mathrm{dl}$; it represented the cumulative dose of lead exposure between the beginning of employment and at the beginning of the calendar year when the TTP started.

\section{Questionnaires}

One of the key questions on the waiting time to pregnancy was phrased as follows: "How many menstrual cycles did it take to get pregnant after you had practised regular sexual intercourse without using any method of birth control?". ${ }^{26}$ We asked about the last method of birth control and the exact time they stopped the practice to validate the exact TTP. If they used intrauterine devices, the TTP data were collected only when regular menstrual cycles could be ascertained after the intrauterine devices were removed. ${ }^{27}$ We also tried to confirm the date of first unprotected pregnancy. Somewhat predictably, since most Taiwanese women are unaware of their husbands' occupational exposure rates, ${ }^{28}$ none in this survey knew the blood lead levels of their husbands. They also did not know our study objective-the relation between lead exposure and fertility. Moreover, our interviewers did not know the women's husbands' $\mathrm{PbB}$ levels before interview. Thus, our assessment of TTP was blind to the level of exposure.

Data on previous medical and occupational histories, and lifestyle factors such as smoking, and use of alcohol, tea, or other caffeinated beverages during each TTP for each couple (both husband and wife) were collected. In particular, husbands were asked about any illness or condition that could impair their ability to become a father, such as parotitis, orchitis, varicocele, or major systemic diseases. Wives were asked about their previous history: age at

\section{Policy implications}

- The current occupational standard, $40 \mu \mathrm{g} / \mathrm{dll}$, for blood lead does not provide adequate protection for male workers in light of the reproductive health considerations.

menarche, duration of the menstrual cycle, any treatment for menstrual irregularity, infertility, pelvic inflammatory disease, or endometriosis, and major abdominal surgery. Additional data on employment status and the main job tasks of the wife were collected for 12 months preceding each pregnancy. We also collected detailed data on the following potential confounding variables: men's and women's age at the beginning of pregnancy, exact date for each pregnancy, pregnancy sequence, and outcome.

\section{Inclusion and exclusion criteria}

Thirty male workers were excluded because of difficulty to recall accurate TTP for the following reasons: spouse deceased or divorced $(\mathrm{n}=3$, including 5 live births), four couples diagnosed as infertile (one husband with varicocele, three with unknown causes but failure to become pregnant within 24 menstrual cycles), spouses with previous habitual abortions $(\mathrm{n}=3$, including 2 live births and 10 spontaneous abortions), spouses with irregular menses $(n=1$, including 2 live births), and having the last delivery more than 14 years previously ( $\mathrm{n}=19$, including 64 live births).

A total of 133 couples were thus included, consisting 321 pregnancies (fig 1). Forty one pregnancies were also excluded because of potentially large measurement errors or biases: inability to recall accurate TTP ( 19 pregnancies with 8 in the non-exposed group and 11 in the exposed group), contraceptive failures or unplanned pregnancies (18 pregnancies with 11 in the non-exposed and 7 in the exposed group), vaginal spotting found after stopping the use of an intrauterine device for longer than two months (2 pregnancies), and wives with endometriosis (2 pregnancies). The remaining 280 pregnancies qualified for analysis, which included 18 artificial abortions, two stillbirths ( 1 in the exposed and 1 in the non-exposed group), eight spontaneous abortions ( 4 in the exposed and 4 in the non-exposed group), and 252 live births.

\section{Statistical analysis}

The outcome variable is the TTP; the exposure variables include males exposed to lead at the beginning of the calendar year when TTP started (five levels), ICL (four levels), and female lead exposure at the beginning of the calendar year when TTP started (yes/no). The potential confounding variables related to TTP included factors for males such as age at the beginning of TTP, use of tea or coffee, use of alcohol, and smoking, and female factors such as age at the beginning of TTP, use of tea, use of alcohol, smoking, contraceptive use before TTP, age at menarche, shift at work, calendar year of pregnancy, and pregnancy sequence.

Fecundability denotes the probability of obtaining a clinically recognised pregnancy in a menstrual cycle among couples not pregnant during previous cycles. The fecundability ratio (FR) measures the odds of a conception among the exposed divided by the odds among those not exposed. FRs were calculated with 95\% confidence intervals (CIs) using the Cox proportional hazards regression model with discrete ties $^{29}$ to evaluate the effect of lead exposure. We censored TTPs of more than 13 cycles to avoid medical intervention, and because $97.5 \%$ of TTPs conceived within 


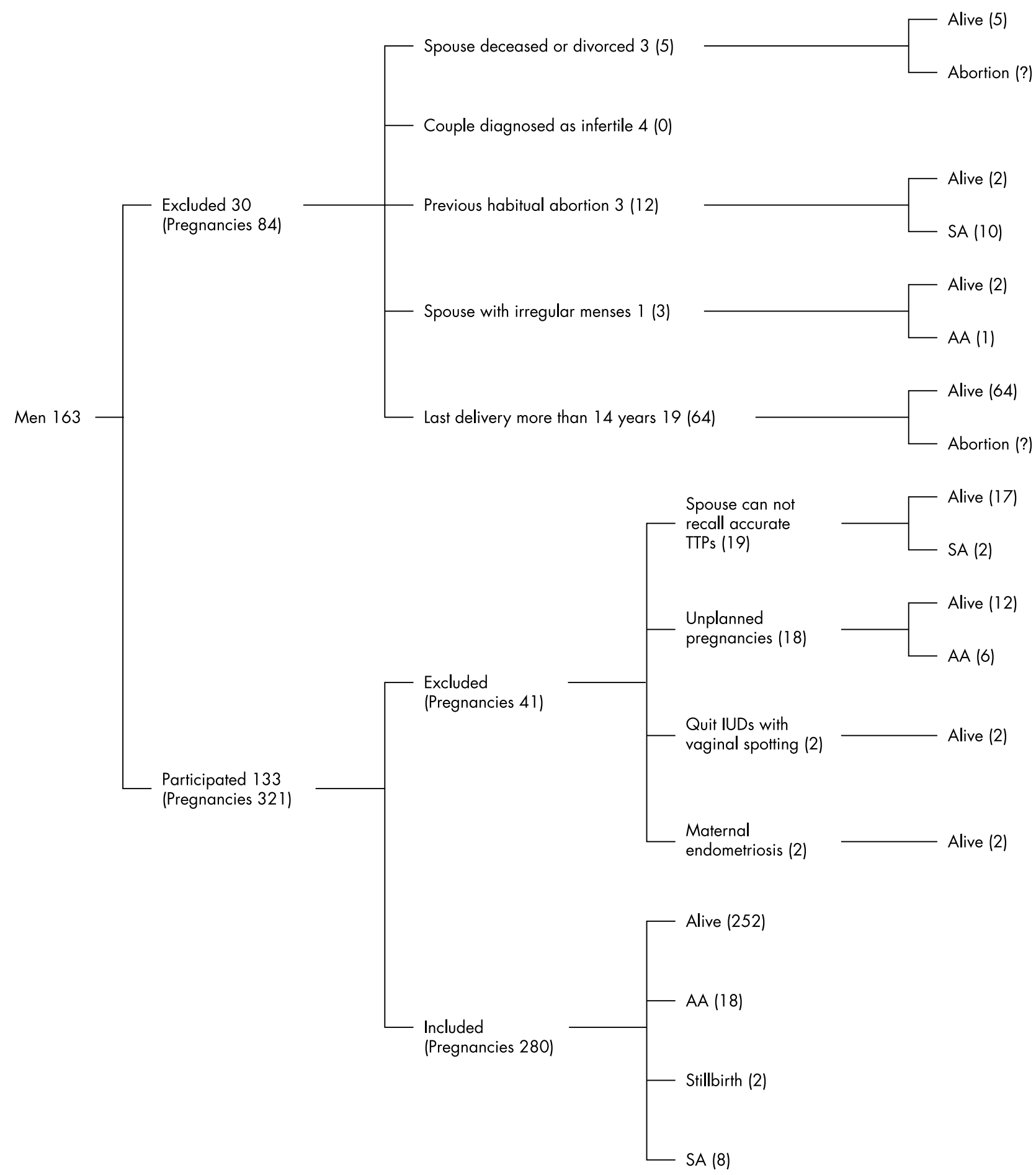

Figure 1 Process of case selection. Numbers in parentheses indicate numbers of pregnancies. AA, artificial abortion; SA, spontaneous abortion; ?, unknown.

one year of unprotected intercourse. In the multiple regression models, we used a change-in-estimate criterion to identify confounding variables. We included multiple pregnancies per couple, violating the assumption of independence and causing underestimation of the variance. Thus, we also randomly selected one pregnancy per couple and restricted the first pregnancy only in the models.

Moreover, we conducted a self comparison analysis for couples with a pregnancy before lead exposure and another one after the exposure. The difference in TTP between the two pregnancies was used as the outcome variable, and male lead levels at the beginning of the TTP and ICL of the later pregnancy were used as exposure variables for constructing linear regression models.

\section{RESULTS}

Table 1 shows no significantly different distribution of various pregnancy outcomes stratified by blood lead levels in men at the beginning of the calendar year when time to pregnancy started. The distributions of TTPs by PbB categories in men revealed that wives of men with higher blood lead levels generally took more cycles to become 


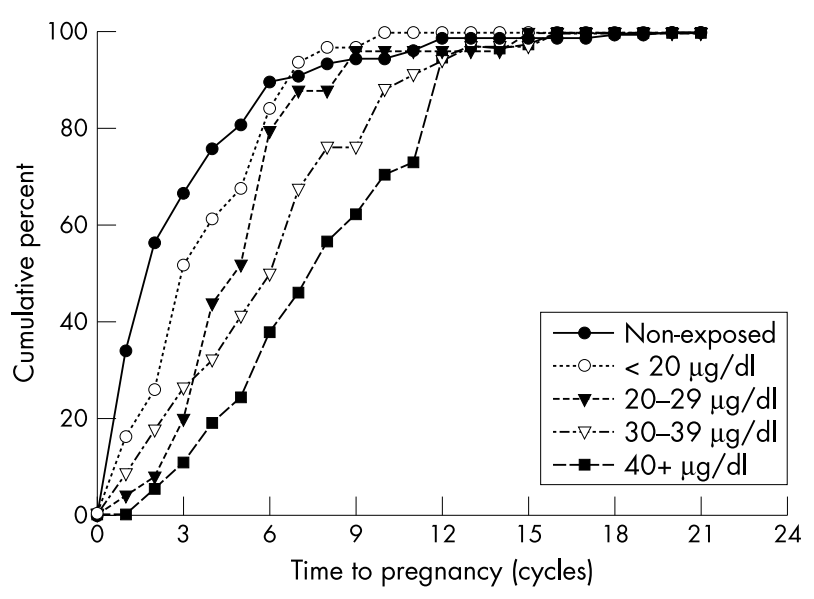

Figure 2 Cumulative distribution of time to pregnancy by blood lead categories in men at the time when time to pregnancy started.

pregnant (table 2). The trend can further be visualised in fig 2 , in which the cumulative distribution of TTP showed a shiftto-right phenomenon as blood lead levels increased.

Table 2 also shows the distribution of potential confounding factors by blood lead level in men at the beginning of the calendar year when time to pregnancy started. Table 3 lists the distribution and crude FRs for all variables being potentially associated with the pregnancy outcomes. Lead exposure in both men and women was significantly associated with decreased fecundability, while none of the other factors showed a statistically significant association with TTP.

The FR decreased with successively higher male blood lead levels, significant at $30 \mu \mathrm{g} / \mathrm{dl}$ ( $\mathrm{FR}=0.50,95 \%$ CI 0.34 to 0.74 ) and $\geqslant 40 \mu \mathrm{g} / \mathrm{dl}$ ( $\mathrm{FR}=0.38,95 \%$ CI 0.26 to 0.56 ) for all valid pregnancies (table 4). Furthermore, maternal exposure to lead showed decreased FR although it was not statistically significant ( $F R=0.61,95 \%$ CI 0.37 to $1.01 ; p=0.06)$. When algorithms restricted the analysis to the first TTP or a randomly selected pregnancy in each couple, the effect of lead exposure still showed consistent results with minor changes. Interaction in terms of lead exposure in men and women was also attempted but no significant interaction effect was found. Moreover, we also found similar results using ICL in multivariable models (data not shown).
For the 41 couples with at least one pregnancy before exposure to lead content in an occupational environment in men and another pregnancy after working at a lead plant, there was a prolonged TTP difference due to lead exposure. The TTP difference was prolonged for 0.15 cycles when $\mathrm{PbB}$ in men increased by $1.0 \mu \mathrm{g} / \mathrm{dl}\left(\mathrm{R}^{2}=0.62, \mathrm{p}<0.0001\right)$ (fig 3$)$. However, no significant result was found using ICL in the models (data not shown).

\section{DISCUSSION}

Although male blood lead levels below $40 \mu \mathrm{g} / \mathrm{dl}$ may impair fecundity in animal experiments, ${ }^{17-19}$ no human epidemiological study has supported this. ${ }^{13} 14$ To our knowledge, this study is the first to show that decreased fecundity or prolonged TTP is significantly associated with $\mathrm{PbB}$ less than $40 \mu \mathrm{g} / \mathrm{dl}$ in men regardless of the lead level representing the exposure when TTP starts. ICL also shows a statistically significant determinant in the likelihood ratio test but does not illustrate a linear association on its plot against difference between TTPs. We believe that the concurrent blood lead level in men, instead of cumulative lead (ICL) exposure, is the major factor associated with reduced fecundity.

We note the following reasons, however, to argue for the probable causal relation and the need for consideration to lower the occupational standard for blood lead levels. First, we have put all the major potential confounders reported into our multivariable modelling strategy, including cigarette smoking, ${ }^{3031}$ alcohol consumption, ${ }^{32}$ use of coffee or tea, ${ }^{33}$ age at the beginning of TTP, ${ }^{34}$ pregnancy sequence, ${ }^{35}$ and maternal lead exposure. ${ }^{36}$ As the typical Taiwanese culture is not conducive for women who smoke or drink, both were not prevalent among the women in this study. Thus, none of these factors can explain the association.

Second, the assumption of statistical independence may be violated because of an underestimation of the variance when the study included more than one TTP estimate per couple. To evaluate this potential bias, we restricted the analysis to the first pregnancy or one randomly selected pregnancy from each couple in the models. Although the sample sizes are thus decreased in each exposure group, the effect is still consistent.

Third, we have deliberately eliminated all TTP related biases through a careful study design. ${ }^{23}$ Women in this study were unaware of their husbands' $\mathrm{PbB}$, and we have verified each question of the interview data as conducted by the same interviewer, resulting in minimal bias. To prevent possible

Table 1 Frequency distribution of various pregnancy outcomes stratified by blood lead levels in men at the beginning of the calendar year when time to pregnancy started

\begin{tabular}{|c|c|c|c|c|c|c|}
\hline & \multirow[b]{2}{*}{ Non-exposed } & \multicolumn{4}{|c|}{ Blood lead level ( $\mu \mathrm{g} / \mathrm{dll})$} & \multirow[b]{2}{*}{ Total } \\
\hline & & $<\mathbf{2 0}$ & $20-29$ & $30-39$ & $\geqslant 40$ & \\
\hline \multicolumn{7}{|l|}{ Pregnancies in the study } \\
\hline Alive & 138 & 27 & 23 & 31 & 33 & 252 \\
\hline Artificial abortion & 10 & 3 & 2 & 1 & 2 & 18 \\
\hline Stillbirth & 1 & - & - & - & 1 & 2 \\
\hline Spontaneous abortion & 4 & 1 & - & 2 & 1 & 8 \\
\hline \multicolumn{7}{|l|}{ Unplanned pregnancy } \\
\hline Álive & 9 & 1 & 1 & - & 1 & 12 \\
\hline Artificial abortion & 2 & 2 & - & 1 & 1 & 6 \\
\hline \multicolumn{7}{|l|}{ Maternal endometriosis } \\
\hline Alive & 1 & - & 1 & - & - & 2 \\
\hline \multicolumn{7}{|l|}{ Cannot recall accurate TTP } \\
\hline Alive & 7 & 3 & 3 & 1 & 3 & 17 \\
\hline Spontaneous abortion & 1 & - & - & - & 1 & 2 \\
\hline \multicolumn{7}{|l|}{ Quit IUD with vaginal spotting } \\
\hline Alive & 1 & - & - & 1 & - & 2 \\
\hline
\end{tabular}


Table 2 Distribution of time to pregnancies in menstrual cycle and potential confounding factors by blood lead level in men at
the beginning of the calendar year when time to pregnancy started

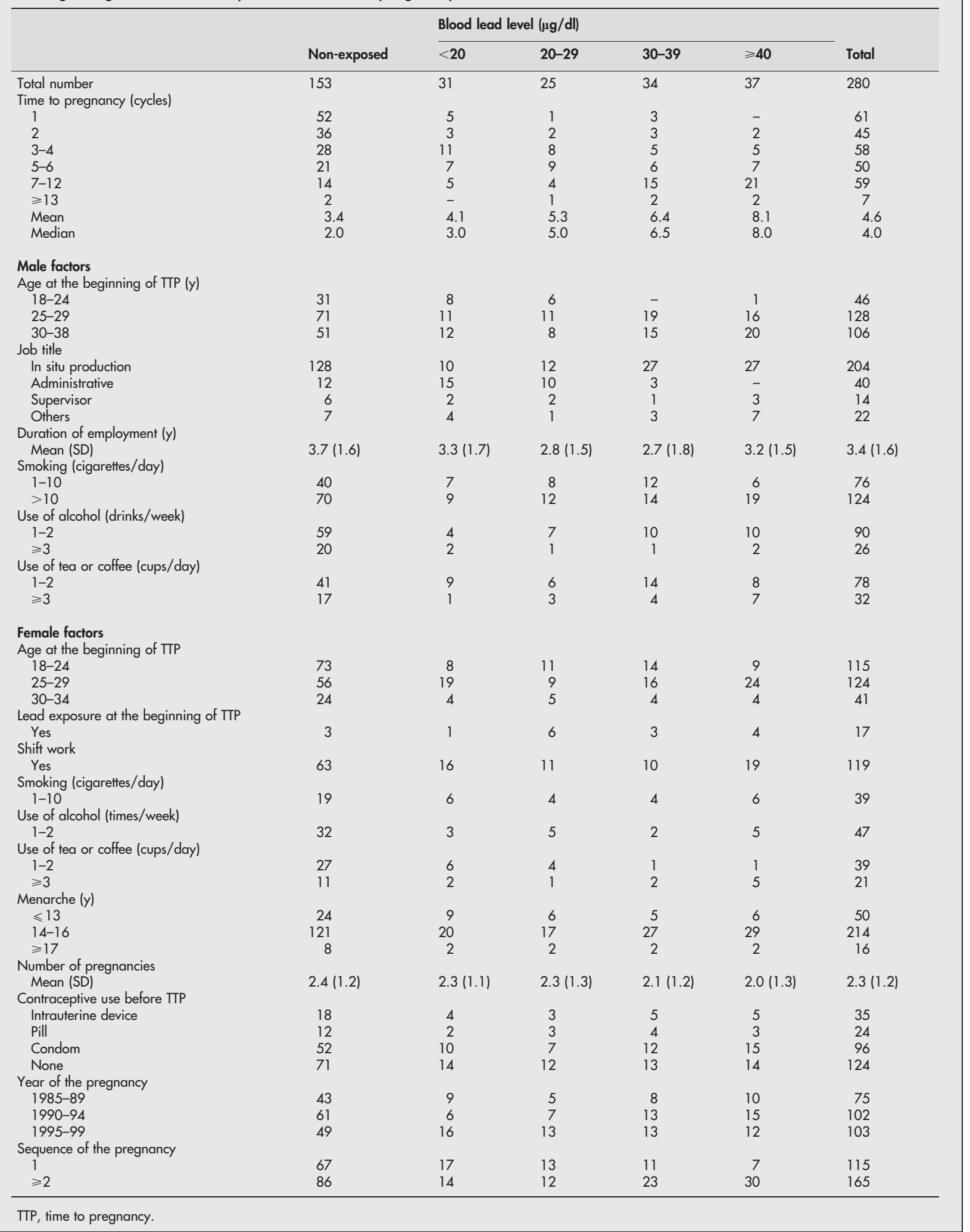

planning bias, we have excluded 18 unprotected pregnancies, $5.5 \%(7 / 127)$ for the exposed group and $7.2 \%(11 / 153)$ for the non-exposed group. Bias due to medical intervention or unhealthy worker effects was eliminated by excluding four couples undergoing infertility treatment. Pregnancy recognition bias was avoided after the exclusion of one couple with extreme irregular menses and three couples with a previous history of habitual abortion. Because the accessibility of medical services has been well documented for workers and their families in Taiwan since $1995,{ }^{37}$ the pregnancies of our subjects were all verified by an obstetrician instead of by home pregnancy test available at local pharmacies. Moreover, 


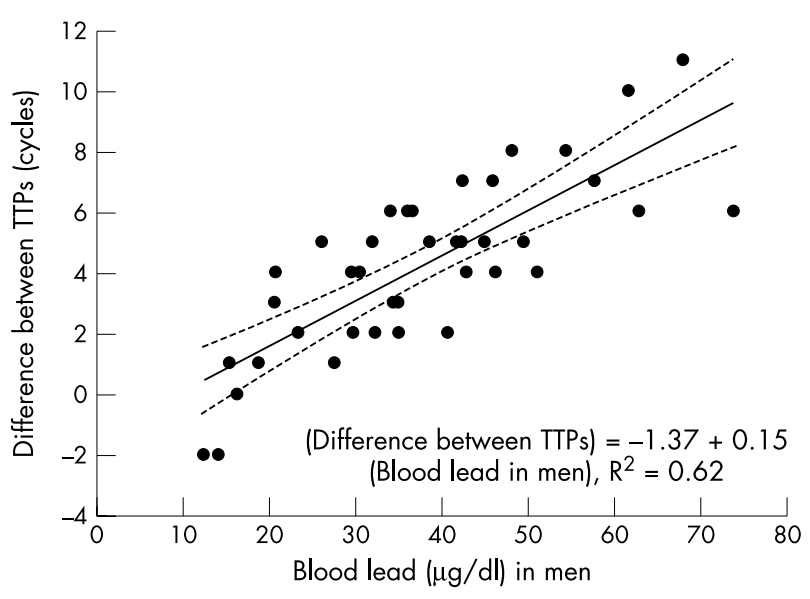

Figure 3 The relation between blood lead levels in men and difference between time to pregnancies (TTPs). Solid line represents the linear regression and dotted lines represent the $95 \%$ confidence intervals.

we have excluded 19 pregnancies with no accurate TTP, to minimise recall bias of TTP.

Fourth, while most European retrospective TTP studies might suffer from time trend bias ${ }^{38}$ (that is, blood lead levels consistently decreased during the observation period), our series did not exhibit such a trend. The annual average blood lead (mean (SD)) levels for men in this study from 1987 to 1999 were 36 (12), 33 (10), 38 (13), 38 (18), 38 (15), 35 (13), 41 (17), 33 (15), 35 (17), 32 (15), 39 (14), 35 (14), and 32 (12).

Finally, we have conducted a self comparison for 41 couples that experienced at least one pregnancy prior to lead exposure and another pregnancy with male exposure at the lead plant. However, $\mathrm{PbB}$ in men was the only significant factor associated with prolonged TTP in the models. This effect remained even after eliminating pregnancies wherein couples were both exposed. Lead toxicity has been associated with impaired semen quality and endocrine function in both human and animal studies; ${ }^{19}$ it is biologically plausible that human exposure may prolong TTP. Based on this study, the magnitude of prolongation is 0.15 cycles per $1 \mu \mathrm{g} / \mathrm{dl}$ increase in blood lead concentration, beginning at the level of $10 \mu \mathrm{g} / \mathrm{dl}$.

The most frequently addressed disadvantage in this study is that the baseline blood lead levels for non-exposed subjects have not been measured. Underestimation of the effect from lead is of concern. Concurrent exposure to other agents, for example, cadmium or other heavy metals is unlikely in a battery factory. Furthermore, the gradual increase in endocrine disrupters from other environmental pollution ${ }^{39}$ may also constitute some kind of superimposed damage to the human reproductive system and push effect measurement towards null values. If the misclassification in exposure status is dismissed, the measured FR would be strengthened.

Joffe and colleagues ${ }^{22}$ reported that the TTP collected using a brief questionnaire is valid at a group level with a median recall time of 14 years in England. We used the same collection methods with our semiconductor study, ${ }^{26}$ which included a face-to-face interview with women and our interviewer team, blinded to occupational exposure. Moreover, the exclusion of spouses with irregular menses or endometriosis, couples diagnosed with infertility or previous habitual spontaneous abortion, and unplanned pregnancies can avoid inaccurate measurement of TTPs, and although it may underestimate the effects of lead exposure, these exclusions can reduce recall bias to a minimum.

Our results showed lower figures of couples with a diagnosis of infertility, spontaneous abortion, and unplanned pregnancy (fig 1). The couples usually seek a doctor for fertility problems with no childbirth after at least two years of preparation for pregnancy in Taiwan. We excluded the couples with a diagnosis of infertility only, to take account of medical intervention for infertility. Another consideration might be a healthy worker effect. That is, married couples usually attempt conception after marriage according to Chinese custom; thus those with infertility problems will not work in lead exposed plants. Our estimate should be lower than the suspected primary infertility rate $(6.0 \%)$ in Taiwan. ${ }^{40}$ The healthy worker effect may give a lower rate of spontaneous abortion; furthermore, the Chinese culture for childbirth may explain a lower rate of unplanned pregnancies.

Although the frequency of intercourse is associated with probability of conception, it has been suggested that it is not essential to collect such information for studies of fecundability. ${ }^{41}$ If intercourse information is not available, this may obscure reproductive effects of an agent that affects the libido. Although we attempted to collect this information, we are concerned that the quality may be poor. Taiwan is a traditional Chinese culture in which the measurement of sexual life is difficult. Imprecision using this data will tend to produce non-differential misclassification.

Our findings are inconsistent with three previous TTP studies in men exposed to lead at similar exposure levels. Apostoli et al found that a statistically significant longer TTP was associated with an exposure level of at least $40 \mu \mathrm{g} / \mathrm{dl} .{ }^{13}$ Sallmén et al found that men with blood lead concentrations above $30 \mu \mathrm{g} / \mathrm{dl}$ had relatively lower fertility, but no clear dose-response relation existed. ${ }^{14}$ On the other hand, Joffe et al found no detectable effect on male fertility in European worksites. ${ }^{15}$ The effect found in this study appears to be a dose-response relation between blood lead and decreased fecundity. Although the reasons for the discrepancies among the findings in the different studies are unclear, face-to-face interviews with workers and their wives to collect data on TTP and other related factors are worth mentioning in this study.

We also found that the workers exposed to lead with delayed pregnancies caught up after 12 months (fig 2). Although we excluded the couples with a diagnosis of infertility, this would imply that the prevalence of infertility did not increase in men exposed to lead at these levels. The findings do not conform with the recent study by Bonde and colleagues, ${ }^{4}$ indicating that there was no linear trend of lower sperm concentration with increasing blood lead, and sperm count does not reduce at exposure levels below $45 \mu \mathrm{g} / \mathrm{dl}$. However, the latter study focused on sperm count and sperm chromatin structure other than seminal characteristics such as morphology or motility or male mediated reproductive effects as early fetal losses, which might also be adversely effected by lead exposure and have an impact on the fecundability.

Our data also support the contention that concurrent blood lead level is a more adequate indicator for reducing male fecundity than cumulative lead exposure. One of the possible reasons could be that the ICL could not differentiate between short term high exposure and long term low exposure. Since the half-life of lead in blood is about $28-30$ days ${ }^{42}$ if there were any cumulative effect of lead on reproduction, relying on blood concentrations alone would be insufficient.

The present study corroborates the hypothesis that decreased fecundity is significantly associated with male 
Table 3 Crude fecundability ratios according to lead exposure and potential confounding factors; univariate Cox discrete proportional hazard models

\begin{tabular}{|c|c|c|c|c|}
\hline Factors & $\begin{array}{l}\text { Pregnancy } \\
\text { no. }\end{array}$ & $\%$ & $\begin{array}{l}\text { Fecundability } \\
\text { ratio }\end{array}$ & $95 \% \mathrm{Cl}$ \\
\hline \multicolumn{5}{|c|}{ Male factors } \\
\hline \multicolumn{5}{|c|}{$\begin{array}{l}\text { Lead exposure at the beginning of the calendar } \\
\text { year when TTP started }(\mu \mathrm{g} / \mathrm{dl})\end{array}$} \\
\hline Non-exposed $\dagger$ & 153 & 54.6 & 1.00 & \\
\hline$<20$ & 31 & 11.1 & 0.86 & 0.58 to 1.27 \\
\hline $20-29$ & 25 & 8.9 & $0.64^{*}$ & 0.42 to 0.98 \\
\hline $30-39$ & 34 & 12.2 & $0.49^{* * *}$ & 0.34 to 0.72 \\
\hline$\geqslant 40$ & 37 & 13.2 & $0.37^{* * *}$ & 0.25 to 0.53 \\
\hline \multicolumn{5}{|l|}{$I C L$ exposure $(\mu \mathrm{g} / \mathrm{dl})$} \\
\hline Non-exposed $\dagger$ & 153 & 54.6 & 1.00 & \\
\hline$<80$ & 56 & 20.0 & $0.59^{*}$ & 0.43 to 0.80 \\
\hline $80-149$ & 32 & 11.5 & $0.44^{* * *}$ & 0.27 to 0.67 \\
\hline$\geqslant 150$ & 39 & 13.9 & $0.36^{* * *}$ & 0.26 to 0.51 \\
\hline \multicolumn{5}{|c|}{ Age at the beginning of TTP } \\
\hline $18-24$ & 46 & 16.4 & 1.34 & 0.95 to 1.90 \\
\hline $25-29+$ & 128 & 45.7 & 1.00 & \\
\hline $30-38$ & 106 & 37.9 & 0.90 & 0.70 to 1.17 \\
\hline \multicolumn{5}{|c|}{ Smoking (cigarettes/day) } \\
\hline Non-smoker† & 80 & 28.6 & 1.00 & \\
\hline $1-10$ & 76 & 27.1 & 1.13 & 0.82 to 1.54 \\
\hline$>10$ & 124 & 44.3 & 1.04 & 0.78 to 1.38 \\
\hline \multicolumn{5}{|c|}{ Use of alcohol (drinks/week) } \\
\hline$<1 \dagger$ & 174 & 62.1 & 1.00 & \\
\hline $1-2$ & 80 & 28.6 & 0.91 & 0.70 to 1.17 \\
\hline$\geqslant 3$ & 26 & 9.3 & 1.12 & 0.74 to 1.69 \\
\hline \multicolumn{5}{|c|}{ Use of tea or coffee (cups/day) } \\
\hline$<1 \dagger$ & 170 & 60.7 & 1.00 & \\
\hline $1-2$ & 78 & 27.9 & 0.98 & 0.74 to 1.27 \\
\hline$\geqslant 3$ & 32 & 11.4 & 0.99 & 0.68 to 1.44 \\
\hline \multicolumn{5}{|c|}{ Female factors } \\
\hline \multicolumn{5}{|c|}{ Age at the beginning of TTP } \\
\hline $18-24$ & 115 & 41.1 & 0.95 & 0.67 to 1.36 \\
\hline $25-29+$ & 124 & 44.3 & 1.00 & \\
\hline $30-34$ & 41 & 14.6 & 0.88 & 0.46 to 1.59 \\
\hline \multicolumn{5}{|c|}{$\begin{array}{l}\text { Lead exposure at the beginning of the calendar } \\
\text { year when TTP started }\end{array}$} \\
\hline Not & 263 & 93.9 & 1.00 & \\
\hline Yes & 17 & 6.1 & $0.59^{*}$ & 0.36 to 0.96 \\
\hline \multicolumn{5}{|l|}{ Shift work } \\
\hline Not & 264 & 94.3 & 1.00 & \\
\hline Yes & 16 & 5.7 & 0.72 & 0.39 to 1.33 \\
\hline \multicolumn{5}{|c|}{ Smoking (cigarettes/day) } \\
\hline Non-smoker† & 241 & 86.1 & 1.00 & \\
\hline $1-10$ & 39 & 13.9 & 0.93 & 0.66 to 1.31 \\
\hline \multicolumn{5}{|c|}{ Use of alcohol (times/week) } \\
\hline$<1 \dagger$ & 235 & 83.9 & 1.00 & \\
\hline & 45 & 16.1 & 1.11 & 0.81 to 1.52 \\
\hline Use of tea or coffee ( & & & & \\
\hline$<1 \dagger$ & 220 & 78.6 & 1.00 & \\
\hline $1-2$ & 39 & 13.9 & 1.19 & 0.84 to 1.67 \\
\hline$\geqslant 3$ & 21 & 7.5 & 1.29 & 0.82 to 2.02 \\
\hline Menarche (years) & & & & \\
\hline$\leqslant 13$ & 50 & 17.9 & 1.28 & 0.94 to 1.75 \\
\hline $14-16+$ & 214 & 76.4 & 1.00 & \\
\hline$\geqslant 17$ & 16 & 5.7 & 1.04 & 0.63 to 1.73 \\
\hline Contraceptive use be & & & & \\
\hline Intrauterine device & 35 & 12.5 & 0.77 & 0.49 to 1.08 \\
\hline Pill & 25 & 8.9 & 0.86 & 0.50 to 1.21 \\
\hline Condom & 96 & 34.3 & 1.04 & 0.78 to 1.13 \\
\hline None† & 124 & 44.3 & 1.00 & \\
\hline Year of the pregnanc & & & & \\
\hline $1985-89$ & 75 & 26.8 & 0.98 & 0.73 to 1.33 \\
\hline $1990-94 \dagger$ & 102 & 36.4 & 1.00 & \\
\hline 1995-99 & 103 & 36.8 & 0.78 & 0.59 to 1.02 \\
\hline Sequence of the preg & & & & \\
\hline $1 \dagger$ & 115 & 41.1 & 1.00 & \\
\hline$\geqslant 2$ & 165 & 58.9 & 0.79 & 0.62 to 1.03 \\
\hline $\begin{array}{l}\text { †Reference category. } \\
{ }^{*} \mathrm{p}<0.05 ;{ }^{* *} \mathrm{p}<0.01 \\
\mathrm{ICL} \text {, index of cumulat }\end{array}$ & 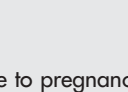 & & & \\
\hline
\end{tabular}

exposure to lead when the concurrent blood lead level is less than $40 \mu \mathrm{g} / \mathrm{dl}$. The current occupational standard, $40 \mu \mathrm{g} / \mathrm{dl}$, for blood lead does not provide adequate protection for male workers. The appropriate blood lead level for men requires exploration in the light of reproductive health considerations. 
Table 4 Adjusted fecundity ratio according to lead exposure and confounding factors; multivariable Cox discrete proportional hazard models

\begin{tabular}{|c|c|c|c|c|c|c|}
\hline \multirow[b]{2}{*}{ Factors } & \multicolumn{2}{|c|}{ All valid pregnancies } & \multicolumn{2}{|c|}{$\begin{array}{l}\text { One randomly selected } \\
\text { pregnancy }\end{array}$} & \multicolumn{2}{|c|}{ Restricted to the first pregnancy } \\
\hline & No. & FR $(95 \% \mathrm{Cl})$ & No. & FR $(95 \% \mathrm{Cl})$ & No. & $\mathrm{FR}(95 \% \mathrm{Cl})$ \\
\hline \multicolumn{7}{|c|}{$\begin{array}{l}\text { Male factors } \\
\text { Lead exposure at the beginning of the calendar year } \\
\text { when TTP started ( } \mu \mathrm{g} / \mathrm{dl})\end{array}$} \\
\hline Non-exposed $\dagger$ & 153 & 1.00 & 65 & 1.00 & 67 & 1.00 \\
\hline$<20$ & 31 & $0.91(0.61$ to 1.35$)$ & 21 & 0.88 (0.54 to 1.44$)$ & 17 & $0.88(0.50$ to 1.53$)$ \\
\hline 20 to 29 & 25 & 0.71 (0.46 to 1.09 ) & 15 & $0.66(0.38$ to 1.16$)$ & 13 & $0.62(0.33$ to 1.14$)$ \\
\hline 30 to 39 & 34 & $0.50 *(0.34$ to 0.74$)$ & 17 & $0.50^{*}(0.29$ to 0.89$)$ & 11 & $0.52 *(0.27$ to 0.99$)$ \\
\hline$\geqslant 40$ & 37 & $0.38^{* * *}(0.26$ to 0.56$)$ & 15 & $0.37^{* * *}(0.22$ to 0.64$)$ & 7 & $0.48^{*}(0.23$ to 0.78$)$ \\
\hline \multicolumn{7}{|c|}{$\begin{array}{l}\text { Female factors } \\
\text { Lead exposure at the beginning of the calendar year } \\
\text { when TTP started }\end{array}$} \\
\hline Not & 263 & 1.00 & 124 & 1.00 & 106 & 1.00 \\
\hline Yes & 17 & $0.61 \neq(0.37$ to 1.01$)$ & 9 & $0.62(0.31$ to 1.25$)$ & 9 & $0.69(0.34$ to 1.40$)$ \\
\hline \multicolumn{7}{|c|}{ Age at the beginning of TTP } \\
\hline 18 to 24 & 115 & $1.29(0.98$ to 1.70$)$ & 53 & $1.28(0.88$ to 1.88$)$ & 65 & $0.95(0.64$ to 1.41$)$ \\
\hline 25 to $29+$ & 124 & 1.00 & 60 & 1.00 & 44 & 1.00 \\
\hline 30 to 34 & 41 & $0.83(0.58$ to 1.20$)$ & 20 & $0.76(0.43$ to 1.37$)$ & 6 & $0.57(0.22$ to 1.50$)$ \\
\hline \multicolumn{7}{|c|}{ Sequence of the pregnancy } \\
\hline $1 \dagger$ & 115 & 1.00 & & & & \\
\hline$\geqslant 2$ & 165 & $1.07(0.83$ to 1.38$)$ & & & & \\
\hline \multicolumn{7}{|c|}{$\begin{array}{l}\text { †Reference category. } \\
\mathrm{tp}=0.06 ;{ }^{*} \mathrm{p}<0.05 ;{ }^{* *}<0.001 \text {. } \\
\text { Adjusted with paternal and maternal lead exposure at the beginning of calendar year when TTP started, maternal age at the beginning of TTP, and pregnancy } \\
\text { sequence (all valid pregnancies). } \\
\text { FR, fecundability ratio; TTP, time to pregnancy. }\end{array}$} \\
\hline
\end{tabular}

\section{ACKNOWLEDGEMENTS}

We are grateful to Mrs Lih-Jane Huang and Ms Lih-Huey Chen for their help with data collection and are indebted to Fung-Chang Sung, PhD, Institute of Environmental Health, National Taiwan University College of Public Health, for his welcome comments during drafting.

\section{Authors' affiliations}

C-Y Shiau, J-D Wang, P-C Chen, Institute of Occupational Medicine and Industrial Hygiene, National Taiwan University College of Public Health, Taipei, Taiwan

Funding: This study was supported by grants from National Health Research Institute (DOH88-HR-504 and NHRI-GT-EX89P504P) and National Science Council (NSC91-2320-B-002-168), Taiwan.

\section{REFERENCES}

1 Lancranjan I, Popescu HI, Gavanescu O, et al. Reproductive ability of workmen occupationally exposed to lead. Arch Environ Health 1975;30:396-401.

$2 \mathrm{Ng} \mathrm{TP}$, Goh HH, Ng YL, et al. Male endocrine functions in workers with moderate exposure to lead. $\mathrm{Br} J$ Ind Med 1991;48:485-91.

3 Alexander BH, Checkoway $\mathrm{H}$, van Netten $\mathrm{C}$, et al. Semen quality of men employed at a lead smelter. Occup Environ Med 1996;53:411-16.

4 Bonde JP, Joffe M, Apostoli P, et al. Sperm count and chromatin structure in men exposed to inorganic lead: lowest adverse effect levels. Occup Environ Med 2002:59:234-42.

5 Lindbohm ML, Sallmén M, Anttila A, et al. Paternal occupational lead exposure and spontaneous abortion. Scand J Work Environ Health 1991;17:95-103.

6 Sallmén M, Lindbohm ML, Anttila A, et al. Paternal occupational lead exposure and congenital malformations. J Epidemiol Community Health 1992;46:519-22.

7 Kristensen $\mathbf{P}$, Irgens $L M$, Daltveit AK, et al. Perinatal outcome among children of men exposed to lead and organic solvents in the printing industry. Am J Epidemiol 1993;137:134-44.

8 Lin S, Hwang SA, Marshall EG, et al. Does paternal occupational lead exposure increase the risks of low birth weight or prematurity? Am J Epidemiol 1998;148:173-81.

9 Gennart JP, Buchet JP, Roels $\mathrm{H}$, et al. Fertility of male workers exposed to cadmium, lead, or manganese. Am J Epidemiol 1992;135:1208-19.

10 Lin S, Hwang SA, Marshall EG, et al. Fertility rates among lead workers and professional bus drivers: a comparative study. Ann Epidemiol 1996;6:201-8.

11 Sallmén M, Lindbohm ML, Nurminen M. Paternal exposure to lead and infertility. Epidemiology 2000;11:148-52.
12 Bonde JP, Kolstad H. Fertility of Danish battery workers exposed to lead. Int J Epidemiol 1997;26:1281-8.

13 Apostoli P, Bellini A, Porru S, et al. The effect of lead on male fertility: a time to pregnancy (TTP) study. Am J Ind Med 2000;38:310-15.

14 Sallmén M, Lindbohm ML, Anttila A, et al. Time to pregnancy among the wives of men occupational exposed to lead. Epidemiology, 2000;11:141-7.

15 Joffe M, Bisanti L, Apostoli $\mathrm{P}$, et al. Time to pregnancy and occupational lead exposure. Occup Environ Med 2003:60:752-8.

16 ACGIH. 2002 threshold limit values for chemical substances and physical agents and biological exposure indices. Cincinnati, $\mathrm{OH}$ : American Conference for Governmental Industrial Hygienists, 2002.

17 Pinon-Lataillade G, Thoreux-Manlay A, Coffigny $\mathrm{H}$, et al. Effect of ingestion and inhalation of lead on the reproductive system and fertility of adult male rats and their progeny. Hum Exp Toxicol 1993;12:165-72.

18 Sokol RZ, Okuda H, Nagler HM, et al. Lead exposure in vivo alters the fertility potential of sperm in vitro. Toxicol Appl Pharmacol 1994:124:310-16.

19 Apostoli P, Kiss P, Porru S, et al. Male reproductive toxicity of lead in animals and humans. ASCLEPIOS Study Group. Occup Environ Med 1998:55:364-74.

20 Baird DD, Wilcox AJ, Weinberg CR. Use of time to pregnancy to study environmental exposures. Am J Epidemiol 1986;124:470-80.

21 Baird DD, Weinberg CR, Rowland AS. Reporting errors in time-to-pregnancy data collected with a short questionnaire. Impact on power and estimation of fecundability ratios. Am J Epidemiol 1991;133:1282-90.

22 Joffe M, Villard L, Li Z, et al. Long-term recall of time-to-pregnancy. Fertil Steril 1993;60:99-104

23 Weinberg CR, Baird DD, Wilcox AJ. Sources of bias in studies of time to pregnancy. Stat Med 1994;13:671-81.

24 Liou SH, Yang GY, Wu TN, et al. Assessment of interlaboratory performance on the measurement of blood lead levels in Taiwan adults. Ind Health 1995;33:181-90.

25 Chuang HY, Schwartz J, Tsai SY, et al. Vibration perception thresholds in workers with long term exposure to lead. Occup Environ Med 2000;57:588-94.

26 Chen PC, Hsieh GY, Wang JD, et al. Prolonged time to pregnancy in female workers exposed to ethylene glycol ethers in semiconductor manufacturing. Epidemiology 2002;13:191-6.

27 Vessey MP, Wright $\mathrm{NH}$, McPherson K, et al. Fertility after stopping different methods of contraception. BMJ 1978;1:265-7.

28 Chang PJ, Wang JD. The accuracy of occupational histories obtained from spouses. In: Hogstedt C, Reuterwall C, eds. Progress in occupational epidemiology. Amsterdam: Elsevier Science Publishers B.V., 1988:53-62.

29 Scheike TH, Jensen TK. A discrete survival model with random effects: an application to time to pregnancy. Biometrics 1997;53:318-29.

30 Baird DD, Wilcox AJ. Cigarette smoking associated with delayed conception. JAMA 1985;253:2979-83.

31 Jensen TK, Henriksen TB, Hiollund NH, et al. Adult and prenatal exposures to tobacco smoke as risk indicators of fertility among 430 Danish couples. Am J Epidemiol 1998;148:992-7. 
32 Jensen TK, Hjollund NH, Henriksen TB, et al. Does moderate alcohol consumption affect fertility? Follow up study among couples planning first pregnancy. BMJ 1998;317:505-10.

33 Bolumar F, Olsen J, Rebagliato $M$, et al. Caffeine intake and delayed conception: a European multicenter study on infertility and subfecundity. European Study Group on Infertility Subfecundity. Am J Epidemiol 1997; 145:324-34.

34 Olsen J. Subfecundity according to the age of the mother and the father. Dan Med Bull 1990;37:281-2.

35 Tuntiseranee $\mathbf{P}$, Olsen J, Chongsuvivatwong V, et al. Fecundity in Thai and European regions: results based on waiting time to pregnancy. Hum Reprod 1998; 13:471-7.

36 Sallmén M, Antilla A, Lindbohm ML, et al. Time to pregnancy among women occupational exposed to lead. J Occup Environ Med 1995;37:931-4.
37 Cheng SH, Chiang TL. The effect of universal health insurance on health care utilization in Taiwan: results from a natural experiment. JAMA 1997;278:89-93

38 Weinberg CR, Baird DD, Rowland AS. Pitfalls inherent in retrospective time-toevent studies: the example of time to pregnancy. Stat Med 1993:12:867-79.

39 Mocarelli P, Gerthoux PM, Ferrari E, et al. Paternal concentrations of dioxin and sex ratio of offspring. Lancet 2000;355:1858-63.

40 Chang MC, Lin HS, Tsai YJ. Infertility survey for Taiwan. Taichung, Taiwan: Taiwan Provincial Institute of Family Planning, 1997.

41 Joffe M. Time to pregnancy: a measure of reproductive function in either sex. Asclepios Project. Occup Environ Med 1997; 54:289-95.

42 Rabinowitz M, Wetherill GW, Kopple JD. Studies of human lead metabolism by use of stable isotope tracers. Environ Health Perspect 1974;7:145-53.

\section{$\mathrm{ECHO}$}

Exposure to volatile organic compounds found to be important in the cause of childhood asthma

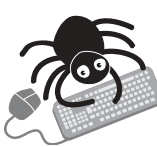

Please visit the Occupational and

Environmental Medicine website [www. occenvmed. com] for a link to the full text of this article.

$\mathrm{T}$ controls. currently accepted recommendations. he role of indoor air quality in the aetiology of asthma has again come under scrutiny in a case-control study from Perth, Western Australia. Children who had received emergency treatment for asthma were found to have been exposed to significantly higher concentrations of volatile organic compounds (VOCs) at home than community

VOCs found in the home include solvents, floor adhesives, paint, cleaning products, furnishings, polishes, and room fresheners. Measurements of VOCs in the homes of 88 cases were made within two weeks of their emergency hospital visit in winter and again in summer. The homes of 104 controls were monitored during the same periods of time. The highest median concentrations were for benzene, followed by toluene and 1,2-dichlorobenzene. In the present study, the concentrations of total VOCs were low, and below

After controlling for potential confounding variables, children exposed to VOCs of $>60 \mu \mathrm{g} /$ $\mathrm{m}^{3}$ (median level of exposure) had a fourfold increased risk of asthma. The highest odds ratios for individual VOCs were for benzene $(2.9,2.3$ to 3.8$)$, ethylbenzene $(2.5,1.2$ to 5.6$)$, and toluene $(1.8,1.4$ to 2.4$)$. For every 10 unit increase in the concentration of toluene and benzene, the risk of having asthma increased by almost two and three times respectively.

VOCs are commonly found in the home, but there is insufficient evidence about their concentrations and effects on health; levels below currently accepted recommendations were found in this study. Further research in this area is now needed.

A Rumchev K, et al. Thorax 2004;59:746-751. 